\title{
In vitro Bioactivities of Aerial Parts of Dioscorea alata
}

\author{
Md. Akbar Hossain ${ }^{1}$, Md. Enamul Haque ${ }^{1}$, Md. Hassan Kawsar ${ }^{2}$ and Md. Sohel Rana ${ }^{1}$ \\ ${ }^{1}$ Department of Pharmacy, Jahangirnagar University, Savar, Dhaka, Bangladesh \\ ${ }^{2}$ Department of Pharmacy, State University of Bangladesh, Dhaka, Bangladesh
}

Received: June 22, 2017; Accepted: July 10, 2017; Published (Web): July 31, 2017

\begin{abstract}
The methanol extract of aerial parts of Dioscorea alata and its organic and aqueous soluble materials were subjected to screenings for antioxidant, cytotoxic, thrombolytic, membrane stabilizing and antimicrobial activities. The polyphenol content and DPPH free radical scavenging assay were conducted to evaluate the antioxidant activity. The total phenolic content was found to vary for different test samples ranging from $23.69 \pm 0.25$ to $26.60 \pm 0.22 \mathrm{mg}$ of GAE/gm of dried extract. In DPPH method the chloroform soluble fraction (CSF) of $D$. alata revealed the highest free radical scavenging activity with $\mathrm{IC}_{50} 25.33 \pm 0.05 \mu \mathrm{g} / \mathrm{ml}$. The petroleum ether soluble fraction (PESF) exhibited highest cytotoxic potential having $\mathrm{LC}_{50}$ value of $6.1 \mu \mathrm{g} / \mathrm{ml}$. During the membrane stabilizing assay, the aqueous soluble fraction (AQSF) inhibited 31.91\% and 47.55\% haemolysis of RBC in hypotonic solution- and heat-induced method, respectively. In thrombolytic assay, the chloroform soluble fraction (CSF) displayed $40.45 \%$ clot lysis. On the other hand the carbon tetrachloride (CTCSF) and chloroform soluble fraction (CSF) revealed mild to moderate antimicrobial activity with zone of inhibition ranging from 8 to $12 \mathrm{~mm}$.
\end{abstract}

Key words: Dioscoreaalata, antioxidant, cytotoxicity, membrane stabilizing, thrombolytic, antimicrobial.

\section{Introduction}

The genus Dioscorea belonging to the family Dioscoreaceae, commonly known as yam, comprises of about 600 species distributed throughout the world, but mostly in tropical regions. Most species contain steroidalsaponins and sapogenins, such as diosgenin, dioscorin, dioscin which are the starting materials for synthesis of many steroidal hormones used as anti-inflammatory agents and contraceptive drugs. D. alata commonly known as 'greater yam' and locally known as 'kathaloo', are climbing perennial vines with heart-shaped leaves (Dattu et al., 2015). Among various yams, D. alata is also known for its high nutritional values with crude protein. Traditionally tuber paste is applied on cancerous wounds, leprosy, gonorrhea and skin diseases. About 2-3 $g$ of paste of the tuber is tied on the infected part to heal. The root contains phytosterols, alkaloids, tannins, carbohydrates and other substances like aluminium, ascorbic acid, beta-carotene, calcium, chromium, cobalt, iron, magnesium, manganese, niacin, potassium, phosphorus, protein, riboflavin, selenium, silicon, sodium, thiamine, tin, zincetc (Chowdhury et al., 2008). D. alata has numerous edible and medical uses, due to its high carbohydrate content in the form of starch. The root is considered to be the ideal source for protein and energy. Recent pharmacognostic studies have demonstrated potent immunomodulatory activities of $D$. alata extracts (Dey and Chaudhuri, 2015). Much works have been done on various medicinal and clinical aspects of the D. alata tubers (Das et al., 2012; Chen et al., 2003), but no such substantial evidence exists on the study with aerial parts of this plant. So, an attempt was made to assess the in vitro bioactivities of the aerial parts of D. alata.

\section{Materials and Method}

Collection of plant materials: Aerial parts of $D$. alata were collected from Dhaka, Bangladesh in

Correspondence to: Md. Akbar Hossain; Cell: +88 01924888885; E-mail: akbar.hab@gmail.com 
October, 2015. The plant was authenticated by an expert botanist of Bangladesh National Herbarium, Mirpur, Dhaka (Accession Number: (DACB) 40388) and a voucher specimen has been submitted for future reference.

Extraction: After proper washing, the aerial parts were sun dried and ground to a coarse powder. Methanolic extract was prepared by $400 \mathrm{~g}$ of powder soaked in 2.5 liters of methanol. The concentrated methanolic extract was partitioned using petroleum ether, chloroform, carbon tetrachloride and aqueous by modified Kupchan partitioning protocol and the resultant partitonates were evaporated to dryness to yield petroleum ether (PESF), carbon tetrachloride (CTCSF), chloroform (CSF) and aqueous (AQSF) soluble fractions. The residues were than stored in a refrigerator until further use.

Table 1. Kupchan partitionates of $D$. alata

\begin{tabular}{lc}
\hline Crude extract/ fraction & D. alata $(\mathrm{g})$ \\
\hline ME & 5.53 \\
PESF & 0.57 \\
CTCSF & 0.63 \\
CSF & 0.42 \\
AQSF & 1.68 \\
\hline
\end{tabular}

$\mathrm{ME}=$ methanolic crude extract; $\mathrm{PESF}=$ pet ether soluble fraction; $\mathrm{CTCSF}=$ carbon tetrachloride soluble fraction; $\mathrm{CSF}=$ chloroform soluble fraction; $\mathrm{AQSF}=$ aqueous soluble fraction.

Total phenolic content: The total phenolic content of the extractives was determined with FolinCiocalteau reagent by using the method developed by Harbertson and Spayd (2006).

$D P P H$ free radical scavenging assay: Following the method developed by Brand-Williams et al., (1995), the antioxidant activity of the test samples was assessed by evaluating the scavenging activities of the stable 1,1diphenyl-2-picrylhydrazyl (DPPH) free radical by using synthetic antioxidants, butylated hydroxyl toluene (BHT) and ascorbic acid as positive controls.

Brine shrimp lethality bioassay: This technique was applied for the determination of general toxic properties of the dimethylsulfoxide (DMSO) solution of plant extractives against Artemia salina in a single day assay (Meyer et al., 1982) by using vincristine sulphate as positive control.

Membrane stabilizing activity: The membrane stabilizing activity of the extractives was evaluated by the inhibition of heat- and hypotonic solutioninduced haemolysis of human erythrocytes following the method developed by Omale et al. (2008).

Thrombolytic activity: The method developed by Prasad et al., (2007) and Harbertson et al. (2006) was used to determine the thombolytic activity by using lyophilised streptokinase (SK) as positive control.

Antimicrobial screening: Antimicrobial activity was determined by the disc diffusion method (Bauer et al., 1966). Five strains of Gram-positive bacteria and eight Gram-negative bacteria were used to evaluate the antimicrobial activity.

Statistical analysis: For all bioassays, three replicates of each sample were used for statistical analysis and the values are reported as mean \pm SD.

\section{Results and discussion}

The crude methanol extracts of aerial parts of $D$. alata as well as their partitionates were evaluated for the total phenolic content, free radical scavenging, cytotoxic, membrane stabilizing, thrombolyticand antimicrobial activities. The total phenolic content of the extractives of $D$. alata was found in the range of $23.687 \pm 0.25$ to $26.603 \pm 0.22 \mathrm{mg}$ of $\mathrm{GAE} / \mathrm{g}$ of extractives, with the highest amount of phenolics (26.603 $\pm 0.22 \mathrm{mg}$ ) being observed in the chloroform (CSF) soluble fraction (Table 2).

In the DPPH free radical scavenging assay, the chloroform (CSF) soluble fraction of $D$. alata revealed maximum free radical scavenging activity $\left(\mathrm{IC}_{50}=25.325 \pm 0.05 \mu \mathrm{g} / \mathrm{ml}\right)$ when compared to ascorbic acid $\left(\mathrm{IC}_{50}=5.80 \mu \mathrm{g} / \mathrm{ml}\right.$ ) (Table 2).

In the brine shrimp lethality bioassay, the pet ether (PESF) soluble fraction of $D$. alata displayed the highest cytotoxic potential with $\mathrm{LC}_{50}$ value $6.10 \pm$ $0.43 \mu \mathrm{g} / \mathrm{ml}$ as compared to $0.45 \mu \mathrm{g} / \mathrm{ml}$ for vincristine sulphate. This suggested the presence of potent 
bioactive components in the above mentioned extractives (Table 2).

The extractives of $D$. alata were assayed for thrombolysis to determine the ability of clot lysis. Addition of $100 \mu$ l streptokinase (SK), a positive control (30,000 I.U.) to the clots of human blood and subsequent incubation for 90 minutes at $37^{\circ} \mathrm{C}$ displayed65.16\% lysis of the clot as compared to distilled water which displaying a negligible lysis of clot (3.09\%). In this study, different extractives of $D$. alata demonstrated significant clot lysis from $11.37 \%$ to $40.45 \%$ (Table 3 ).
The membrane stabilizing activity of the extractives of $D$. alata was also determined. They significantly protected the lysis of human erythrocyte membrane induced by heat and hypotonic solution, as compared to the standard acetyl salicylic acid. In hypotonic solution-induced condition, the aqueous extract of D. alata $(2.0 \mathrm{mg} / \mathrm{ml})$ inhibited $31.91 \%$ haemolysis of RBCs as compared to $43.74 \%$ revealed by acetyl salicylic acid $(0.10 \mathrm{mg} / \mathrm{ml})$ and in heatinduced condition, the aqueous extract inhibited $47.55 \%$ haemolysis of RBCs as compared to $24.97 \%$ shown by standard acetyl salicylic acid $(0.10 \mathrm{mg} / \mathrm{ml})$ (Table 3).

Table 2. Total phenolic content, free radical scavenging and cytotoxic activity of $D$. alata.

\begin{tabular}{lccc}
\hline Test sample & $\begin{array}{c}\text { Total phenolic content (mg of } \\
\text { GAE/g of extractive) }\end{array}$ & $\begin{array}{c}\text { DPPH Free radical scavenging } \\
\text { activity IC } 50(\mu \mathrm{g} / \mathrm{ml})\end{array}$ & $\begin{array}{c}\text { Cytotoxicity } \\
\text { LC }_{50}(\mu \mathrm{g} / \mathrm{ml})\end{array}$ \\
\hline ME & $23.687 \pm 0.25$ & $26.716 \pm 0.85$ & $26.57 \pm 0.18$ \\
PESF & $25.080 \pm 0.05$ & $27.479 \pm 0.22$ & $06.10 \pm 0.43$ \\
CTCSF & $25.599 \pm 0.18$ & $25.937 \pm 0.09$ & $11.33 \pm 0.09$ \\
CSF & $26.603 \pm 0.22$ & $25.325 \pm 0.05$ & $14.04 \pm 0.21$ \\
AQSF & $24.027 \pm 0.32$ & $25.403 \pm 0.14$ & $57.62 \pm 0.05$ \\
\hline VS & & & 0.45 \\
BHT & & 23.50 & \\
Ascorbic acid & & 5.8 & \\
\hline
\end{tabular}

$\mathrm{ME}=$ methanolic extract, $\mathrm{PESF}=$ pet ether soluble fraction, $\mathrm{CTCSF}=$ carbon tetrachloride soluble fraction, CSF $=$ chloroform soluble fraction and AQSF = aqueous soluble fraction.

Table 3. Percentage inhibition of hypotonic solution and heat-induced hemolysis of erythrocyte membrane and thrombolytic activity of $D$. alata.

\begin{tabular}{lcccc}
\hline Standard/ Sample & Concentration & \% clot lysis & \multicolumn{2}{c}{ \% inhibition of hemolysis } \\
\hline ME & $(\mathrm{mg} / \mathrm{ml})$ & & hypotonic solution-induced & heat-induced \\
\cline { 3 - 4 } PESF & 2.0 & $27.50 \pm 0.14$ & $15.20 \pm 0.26$ & $17.29 \pm 0.34$ \\
CTCSF & 2.0 & $31.61 \pm 0.34$ & $12.27 \pm 0.58$ & $32.18 \pm 0.48$ \\
CSF & 2.0 & $11.37 \pm 0.56$ & $19.95 \pm 0.87$ & $18.78 \pm 0.24$ \\
AQSF & 2.0 & $40.45 \pm 0.21$ & $12.59 \pm 0.21$ & $29.07 \pm 0.19$ \\
ASA & 2.0 & $25.84 \pm 0.11$ & $31.91 \pm 0.53$ & $47.55 \pm 0.12$ \\
Blank & 0.1 & & $43.74 \pm 0.18$ & $24.97 \pm 0.23$ \\
Streptokinase & & $3.09 \pm 0.25$ & & \\
\hline
\end{tabular}

$\mathrm{ME}=$ methanolic extract, $\mathrm{PESF}=$ pet ether soluble fraction, $\mathrm{CTCSF}=$ carbon tetrachloride soluble fraction, CSF = chloroform soluble fraction and AQSF = aqueous soluble fraction. ASA = acetylsalicylic acid. 
The extractives of $D$. alata when screened for antibacterial activity against five gram positive and eight gram negative bacteria at a concentration of 400 $\mu \mathrm{g} /$ disc, the chloroform (CSF)and the carbontetrachloride (CTCSF) soluble fractions of $D$. alata revealed mild to moderate inhibitory activity against the test pathogens having zone of inhibition ranging from 08.0-12.0 $\mathrm{mm}$. The highest inhibition of bacterial growth of the chloroform soluble fraction
(CSF)(12.0 mm) against Salmonella paratyphi. Same fraction displayed $(11.0 \mathrm{~mm})$ against Shigella dysenteriae and Sarcina lutea (Table 4). On the other hand, the methanolic (ME), pet ether (PESF) and aqueous (AQSF) soluble fractions of $D$. alata exhibited no antimicrobial activity. The inhibitory activity of the extractives was compared with slandered ciprofloxacin (30 $\mu \mathrm{g} /$ disc).

Table 4. Antimicrobial activity of D. alata.

\begin{tabular}{lcccccc}
\hline & \multicolumn{5}{c}{ Test sample (D. alata) } \\
Test microorganism & \multicolumn{5}{c}{ diameter of zone of inhibition (mm) } & Ciprofloxacin \\
\cline { 2 - 5 } & ME & PESF & CTCSF & CSF & AQSF \\
\hline Bacillus cereus & - & - & 10.0 & 10.0 & - & 41.0 \\
Bacillus megaterium & - & - & 7.0 & 7.0 & - & 40.0 \\
Bacillus subtilis & - & - & 7.0 & 7.0 & - & 35.0 \\
Staphylococcus aureus & - & - & 7.0 & 7.0 & - & 38.0 \\
Sarcina lutea & - & - & 8.0 & 11.0 & - & 39.0 \\
Salmonella paratyphi & - & - & 10.0 & 12.0 & - & 36.0 \\
Salmonella typhi & - & - & - & 7.0 & - & 30.0 \\
Vibrio parahemolyticus & - & - & - & - & 34.0 \\
Escherichia coli & - & - & 8.0 & 8.0 & - & 38.0 \\
Vibrio mimicus & - & - & 8.0 & 8.0 & - & 35.0 \\
Shigella dysenteriae & - & - & 11.0 & 11.0 & - & 28.0 \\
Pseudomonas aeruginosa & - & - & 8.0 & 7.0 & - & 40.0 \\
Shigella boydii & - & - & 10.0 & 10.0 & - & 40.0 \\
\hline
\end{tabular}

\section{Conclusion}

It is clearly evident from the above findings that different fractionates of the aerial parts of $D$. alata displayedmild to moderate free radical scavenging, cytotoxic, thrombolytic potential and membrane stabilizing properties. Our findings justify the traditional uses of this plant species. Therefore, the plantis good candidates for further chemical investigations to isolate the active constituents.

\section{Reference}

Abhyankar, R.K. and Upadhyay, R. 2011. Ethno medicinal studies of tubers of Hoshangabad, M.P. Bulletin of Environment. Pharmacology and Life Sciences. 1, 5759.
Bauer, A.W., Kirby, W.M.M., Sheriss, J.C. and Turck, M. 1966. Antibiotic susceptibility testing by standardised single method. Am. J. Clin. Pathol. 45, 493-496.

Brand-Williams, W., Cuvelier, M.E. and Berset, C. 1995. Use of free radical method to evaluate antioxidant activity. Lebensm. Wiss. Technol. 28, 25-30.

Das, A.K., Dutta, B.K., Sharma, G.D. 2008. Medicinal plants used by different tribes of Cachar district, Assam. Indian J. Trad. Know. 7, 446-454.

Dattu, B. 2015. Food and medicinal values of certain species of Dioscorea with special reference to Assam. J. Pharmacogn. Phytochem. 3, 15-18.

Dey, P. and Chaudhuri, T.K. 2015. Phytochemical Analysis of Dioscoreaalata. J. Food Biochem. 5, 1745-1751. 
Harbertson, J. and Spayd, S. 2006. Measuring phenolics in the winery. Am. J. Enol. Vitic. 57, 280-288.

Khumbongmayum, A.D., Khan, M.L. and Tripathi, R.S. 2005. Biodiversity value, status and strategies for their conservation. Biodiver. and Conserv. 14, 5041-82.

Meyer, B.N., Ferringni, N.R., Puam, J.E., Lacobsen, L.B., Nichols, D.E. and McLaughlin, J.L. 1982. Brine shrimp: a convenient general bioassay for active constituents. Planta Med. 45, 31-32.

Omale, J. and Okafor, P.N. 2008. Comparative antioxidant capacity, membrane stabilization, polyphenols composition and cytotoxicity of the leaf and stem of Cissusmultistriata. Afr. J. Biotechnol. 7, 3129-3133.
Prasad, S., Kashyap, R.S., Deopujari, J.Y., Purohit, H.J., Taori, G.M. and Daginawala, H.F. 2007. Effect of Fagoniaarabica (Dhamasa) on in vitro thrombolysis, BMC Complement. Alternat. Med. 7, 7-36.

Purkayastha, J., Dutta, M. and Nath, C.S. 2007. Ethno medicinal plants from Dibru-Saikhowa biosphere reserve, Assam. Indian J. Traditional Knowledge 6, 477-480.

Ray, S., Sheikh, M. and Mishra, S. 2011. Ethno medicinal plants used by tribals of East Nimar region, Madhya Pradesh. Indian J. Tradi. Know. 10, 367-371. 